\title{
WordPress and CiviCRM: Dynamic Integration for Non-Profits
}

\author{
Apurva Bhatkal \\ TCET, \\ Mumbai University \\ Mumbai, India
}

\author{
Prarthna Jajodia \\ TCET, \\ Mumbai University \\ Mumbai, India
}

\author{
Shrinidhi Bhandari \\ TCET, \\ Mumbai University \\ Mumbai, India
}

\author{
Purvi Sankhe \\ Assistant Professor, \\ TCET, \\ Mumbai, India
}

\begin{abstract}
Non Profit organizations are an integral part of the civil society. They are different from both government and business organizations because they are voluntary, self governing and serve the purpose and common goals of their members.

Non-profit revenue sources include fees for membership, service, government grants, individual and corporate donations, member dues, investments, revenues from commercial ventures, and other sources.

The reason most Non-Profits find it difficult to achieve a total 360 degree view of their constituency is technology. Hence, an affordable, user friendly and easy to use solution is needed to manage members, payments, donations and social goals.

A solution that integrates open source CiviCRM and CMS is being built. CMS is used to display and share information with the world while CRM allows personal content segmentation, permission and analysis.

Synchronization of the dynamic duo negates the necessity to manually transfer data leading to faster, cheaper and accurate distribution of information.
\end{abstract}

\section{General Terms}

Data and Information systems, Knowledge extraction and management.

\section{Keywords}

WordPress, CiviCRM, CRM, CMS, PHP, Dashboard, Opensource, Non Profit

\section{INTRODUCTION}

Nonprofit is a generic term that is used to describe institutions that are a part of the nonprofit sector. These nonprofit organizations are distinct from the other sectors - business and government. They differ as they use the surplus revenues to achieve its goals rather than distributing them as profit or dividends. The organizations that are a part of the nonprofit sector are universities, trade unions, Chamber of Commerce, labor unions, etc. The various characteristics of the nonprofit sector are as follows:

1. They are organized
2. They are self governing, i.e they are private

3. They do not distribute profits

4. They are voluntary and self governing.

The nonprofit organizations need to manage their members, membership fees and member dues, manage their events and associated contributions, handle the funds raised and also generate timely reports. Handling such information requires a clear view of the constituency of the nonprofit. Hence, for smooth functioning of the nonprofit, a connected view of all the relationships of the nonprofit is a must to manage information.

Data mappings, code structure, storage of member information and funds, event handling, promotions and permissions, managing historical data are few of the major issues in handling the working of the nonprofit.

A connected view of all the relationships and a centralized system to handle the information and content with accuracy will prove beneficial to achieve the goals of any nonprofit. This can be achieved through a unification of CMS-CRM implementation.

\section{LITERATURE SURVEY}

\subsection{The Role of Non-Profit Organizations in Development: the Experience of the World Bank}

The non-profit sector has shown exponential growth over the past two decades. In India, registered NGOs handle $\$ 520$ million per year, or 25 percent of all external aid. (World Bank, 1996)

Recent findings published by Johns Hopkins University indicate that the non-profit sector employs $7.1 \%$ of the total agricultural work force. It boasts revenue of $\$ 1.311$ trillion inclusive of government contributions, fees and voluntary donations of funds. This means that the non-profit sector can represent citizen concerns, promotes community, address unmet needs, and help improve the quality of life. [1] 


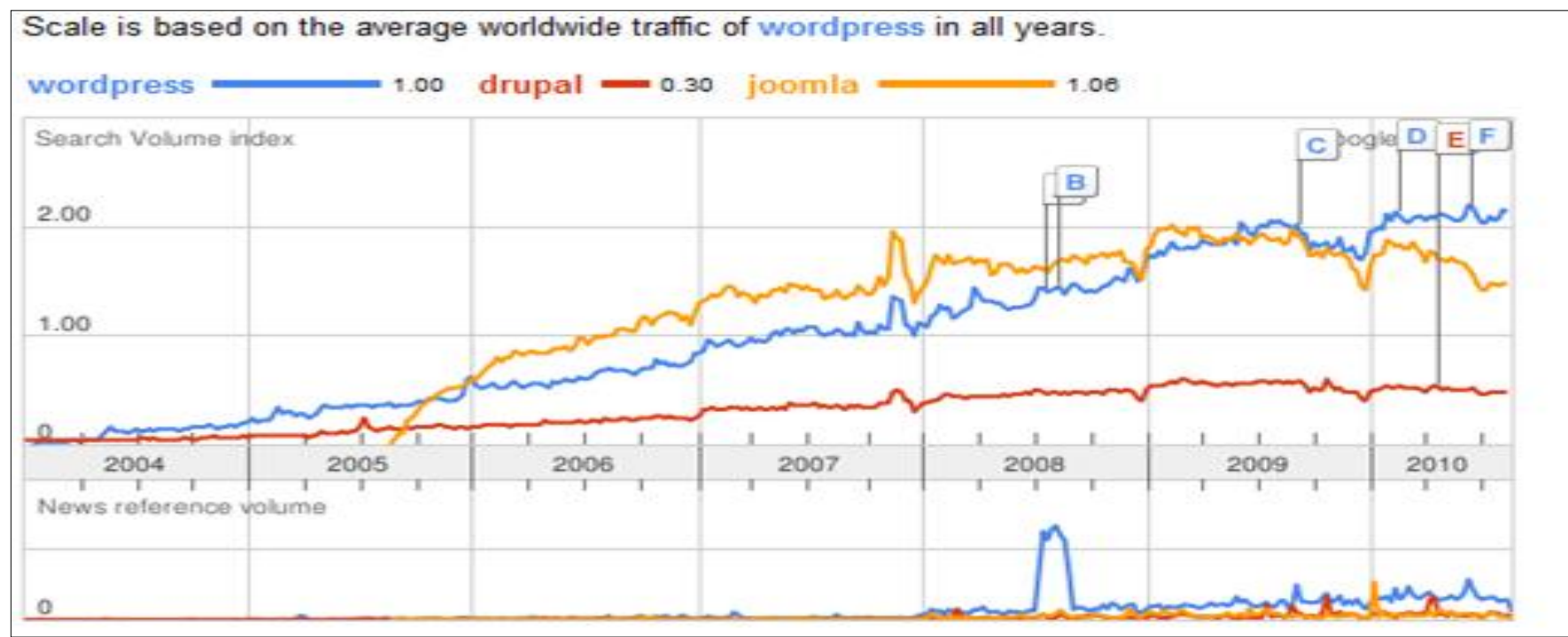

Fig 1: Updated March 2012 Chart: Overall Drupal Vs. WordPress Vs. Joomla vs TYPO3 Trend by Google Trends [3]

The software implementation and management of Nonprofits of the yester years were difficult to use, unstable to operate. Hence, a new open source unification of a centralized content and relationship management is a must and relevant to achieve the goals of the nonprofit.

\subsection{WordPress and CiviCRM : The Dynamic Duo}

Content Management System (CMS) focuses on content than on code. CMS lets us build, manage and publish content easily and is used to track the business directory.

Joomla, Drupal and WordPress are the most famous CMS. All the three competitors are based on PHP and MySQL. Drupal is not lay friendly and doesn't provide users with a range of themes and plugins where as Joomla lacks SEO capabilities. In our implementation we are using WordPress as it allows multiple authors and a strong SEO. Fig 1 shows the popularity of WordPress and the other competetors.

WordPress is free to use, it has minimal server needs, plethora of features, and it has its own digital presence and an integrated ad management.

Constituent Relationship Management (CRM) is an open source-web based Customer Relationship Management tool. CRM systems make work easier to handle, give a transparent view of the nonprofits constituency. This approach to management Instead of just storing data, CRM systems make work easier, more secure, and more meaningful. All divisions access and update information in the same system without fear of data corruption or accidentally updating information they shouldn't be allowed to access.

We are using CiviCRM for implementing the following features:

1. Contact management

2. Contributions
3. Communications

4. Peer-To-Peer Fundraisers

5. Events

6. Members

7. Reports

We are using the duo of WordPress and CiviCRM as both are open source, user friendly, and the integration allows improved permission and form integration.

\section{IMPLEMENTATION}

\subsection{Current Systems}

The project has been implemented for Chamber of Commerce. A Chamber of Commerce is a voluntary organization. The objective of the Chamber is to help groups and individual of a community to network and unite businesses, professional individuals and firms. The major responsibility of the Chamber of Commerce is the community's economic well-being. This is done by creating a cache of resources for the community.

The current systems that most Chambers use are used to represent data and information. There is no unified approach for handling crucial information like new events, managing contents and permissions. There is no 360 degree view of the constituency hence there is a lag in the communication system.

The issues with tailor made software solutions are that they have no technical support after a couple of years and the functionality provided cannot grow with time with customer needs as they are built around the user needs at that particular point in time.

Time is a crucial factor in business. Hence, it is very important to segregate individuals and firms of the Chamber for efficient flow of communication and information. 


\subsection{Proposed Systems}

The current system tries to unify all the operations of the Chamber and create a holistic view of the constituency. The major operations that need to be handled are: member registration and payment of fees, managing their memberships, dues, organizing events and managing them, handling the database efficiently, generating reports, etc.

The system is capable of performing these functions by a dynamic integration of WordPress and CiviCRM. WordPress is built on PHP and MySQL.

\subsection{Methodology}

WordPress is a versatile CMS as it is based on themes and plugins. They are designed to extend functionalities of the basic CMS. The implementation uses a number of plugins like Contact form to email, print friendly, etc. The plugins are customized as per the necessity of the user application. Hence, we can build systems easier and faster in WordPress. Managing and publishing content can now be handled by any lay user. Analysis of information regarding constituents like members and donors is not possible in a CMS. Hence, a solution that can manage, analyze and produce activity reports is a must to handle a complex structure and working of the nonprofit is necessary. The project uses CiviCRM - a plugin to manage members, relationships, etc.

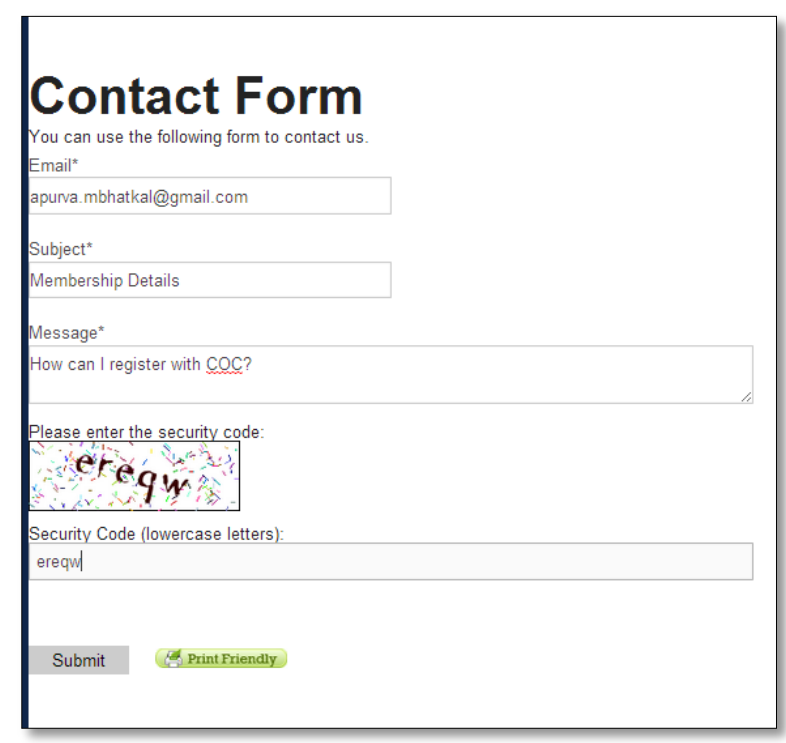

Fig 2: Contact Form in WordPress

The form is customized in CiviCRM and displayed to the user using WordPress for front end. Fig.5 displays the CiviCRM form. Fields can be customized as per needs of the nonprofit. It is integrated with the payment gateway. Fig. 6 displays the confirmation reciept after the payment is received and Fig. 7 displays the auto generated email that the member receives. Fig.8 represents the database schema of the payment table. It displays the registration id, the time the user made the payment, the IP address, etc. Also, auto emails are generated after payment to the member. The administrator can also view this data in the CiviCRM database.
CMS allows the admin to easily handle the data, analyze and report data. This implementation shows how easily data can be handled, stored and used for analysis purpose by easy customization of the plugins. The plugin needs to be downloaded and stored in the wp-contents folder. Fig.2 denotes the Contact Form created in WordPress by using Contact Form to Email.

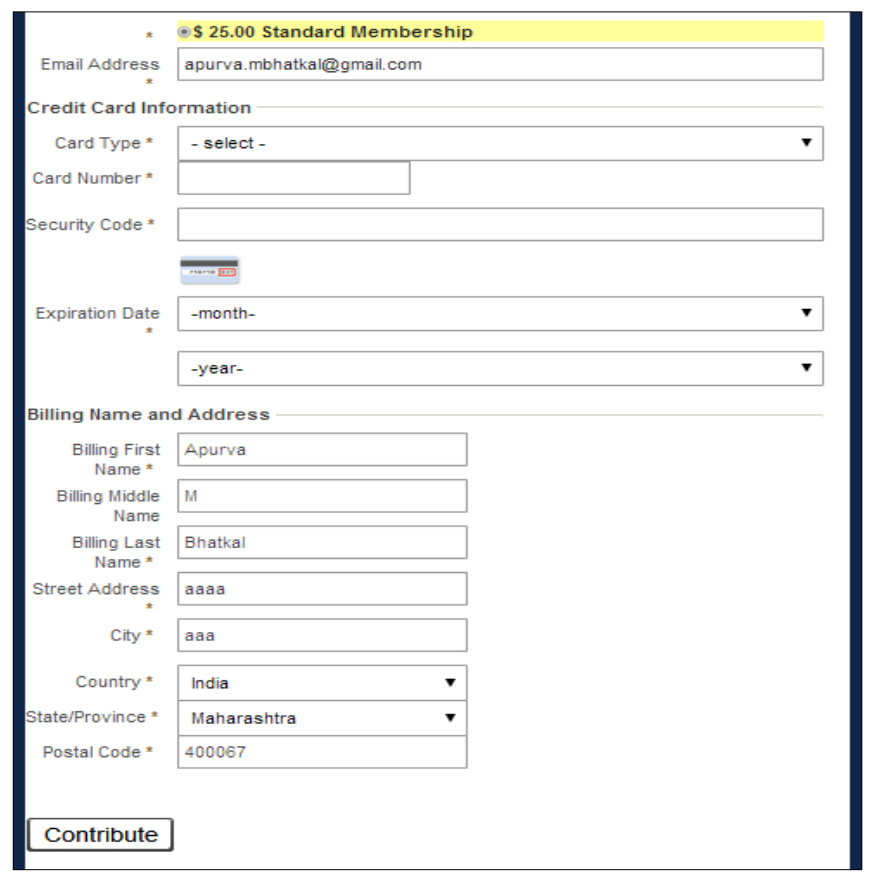

Fig 5: View of the payment form created in CiviCRM and displayed in WordPress

Also, we can handle the database of WordPress through PHPMyAdmin. The administrator need not view the database through PHPMyAdmin as CMS allows easy usage of the content through WordPress dashboard. Fig. 3 represents the data collected from the contact form. Fig.4 represents the admin view through the WordPress dashboard. The administrator need not check the database to add, delete messages. It can be handled through the Dashboard. Hence, managing content becomes easier for the administrator.

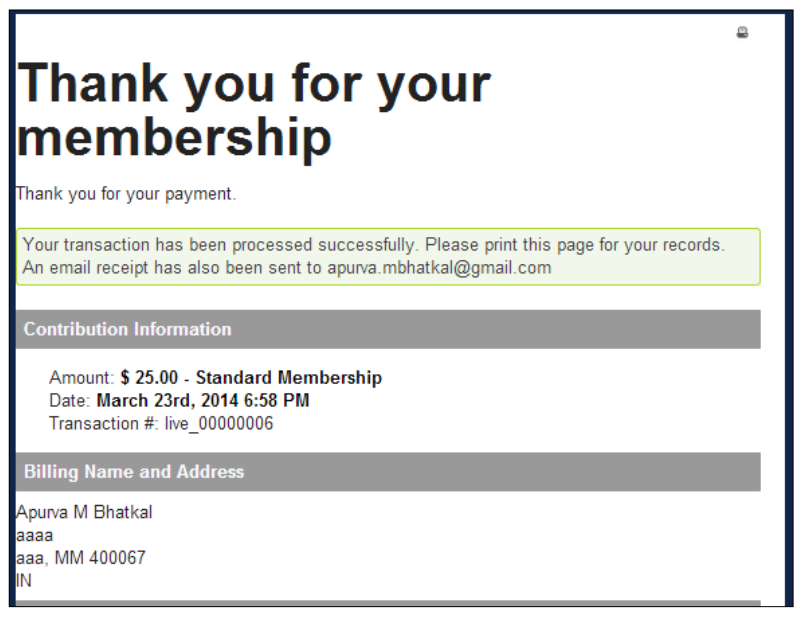

Fig 6: Confirmation receipt generated after successful payment. 
CiviCRM allows the admin to create forms for memberships, registration, donations, etc. Also, integration with payment gateway is possible. For nonprofits, managing members is a crucial. Also, members can be bifurcated by using CiviCRM.

CMS cannot analyze the activities of all members, events, etc. This is implemented by means of CiviCRM. The dynamic integration of the two allows easy form creation, integration, publishing and analysis of data. CiviCRM creates a different database in PHPMyAdmin area, in MySQL. It creates database attributes as per the customization of the forms in the frontend using the CMS. The member information is stored in the database as per the CiviCRM customization. Hence it is flexible and can be used as per needs of the nonprofit.
The dynamic integration of WordPress and CiviCRM eases the working of the nonprofit as the CMS allows easy management of the content.

Social media connectivity is also an integral part of todays lives. We have integrated it with Facebook. Figure 9 represents the same.

Handling and managing events is also an important part of the working of the project.We have provided an option for registering a user to events. Figure 10 depicts the view of the event registration.

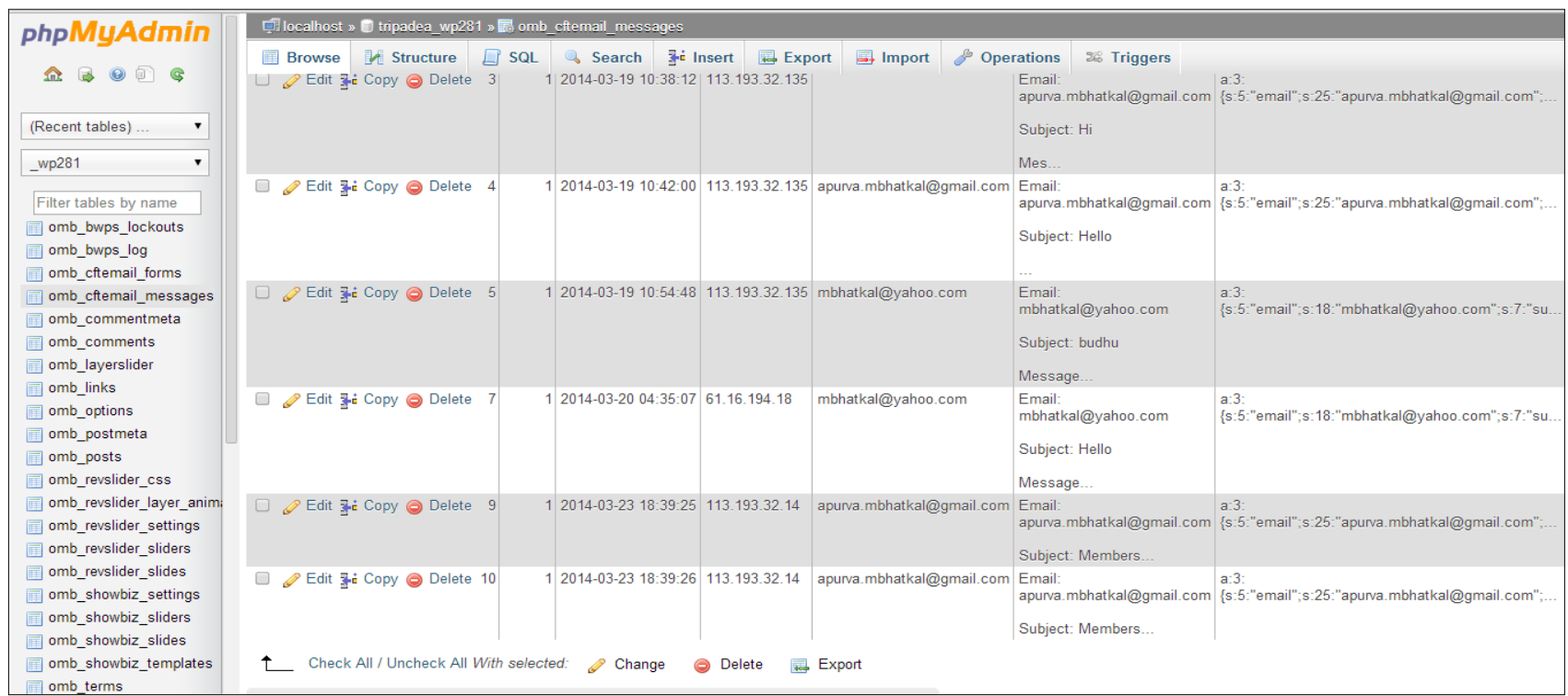

Fig 3: Database view of WordPress showing data of the Contact Form

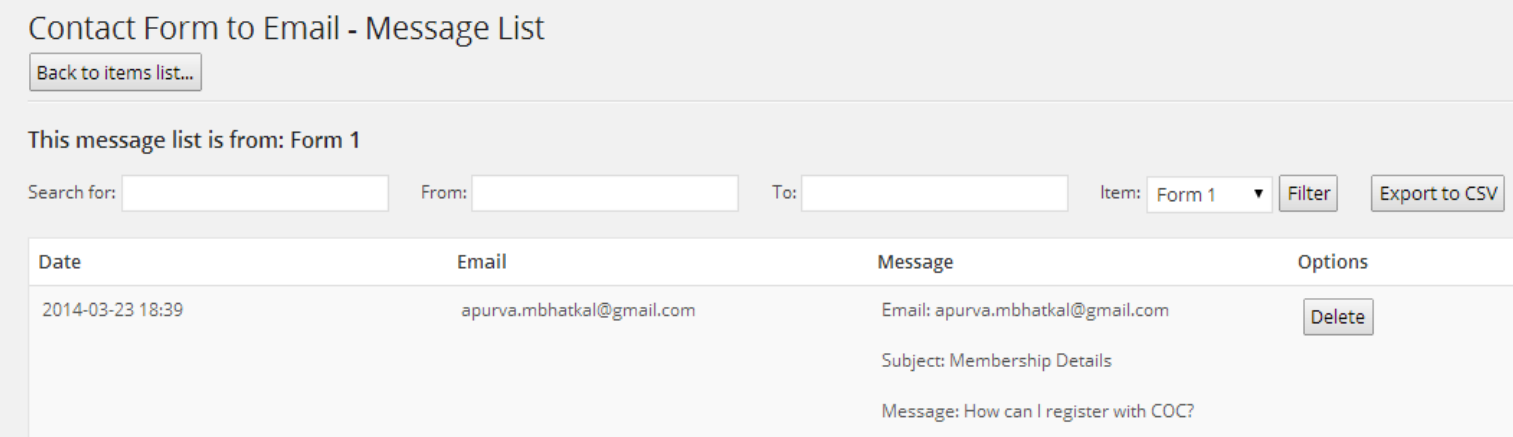

Fig 4: WordPress - Dashboard view of Contact Form

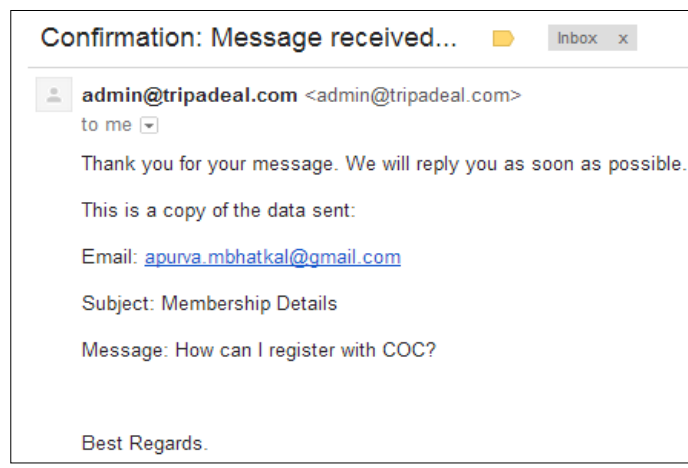

Fig 7: Email received after successful payment.

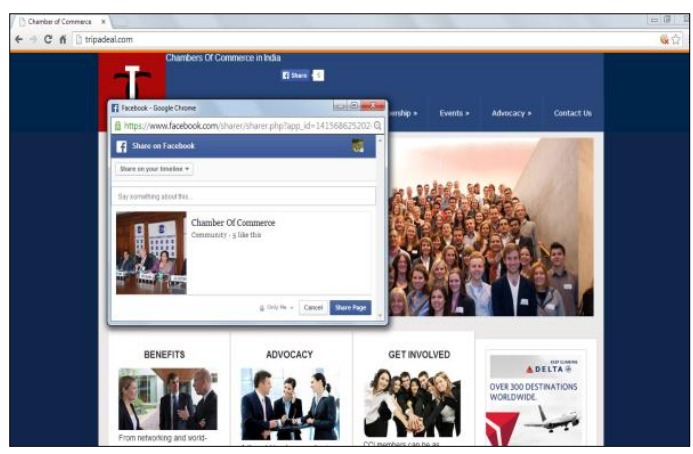

Fig 9: Social Media Connectivity 


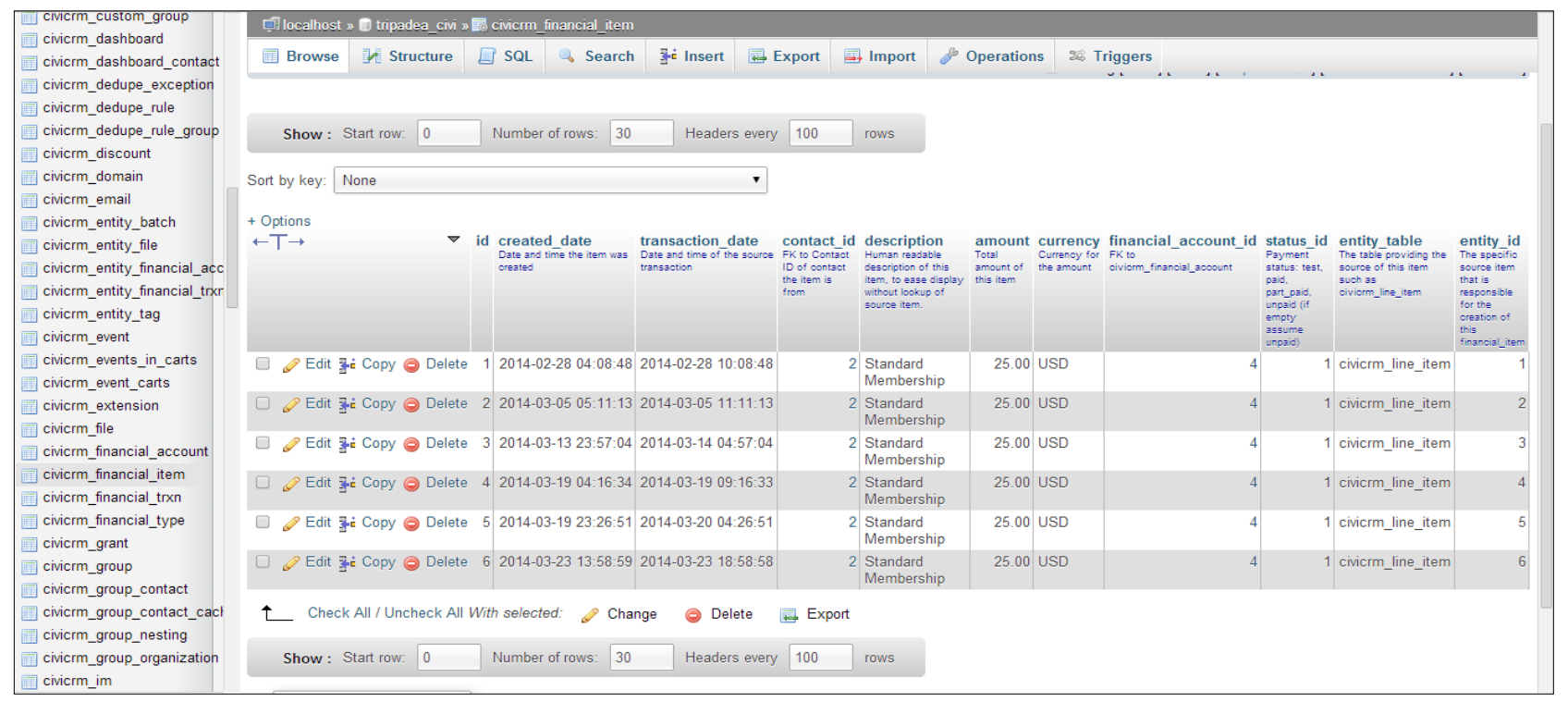

Fig 8: Database view of the CiviCRM database.

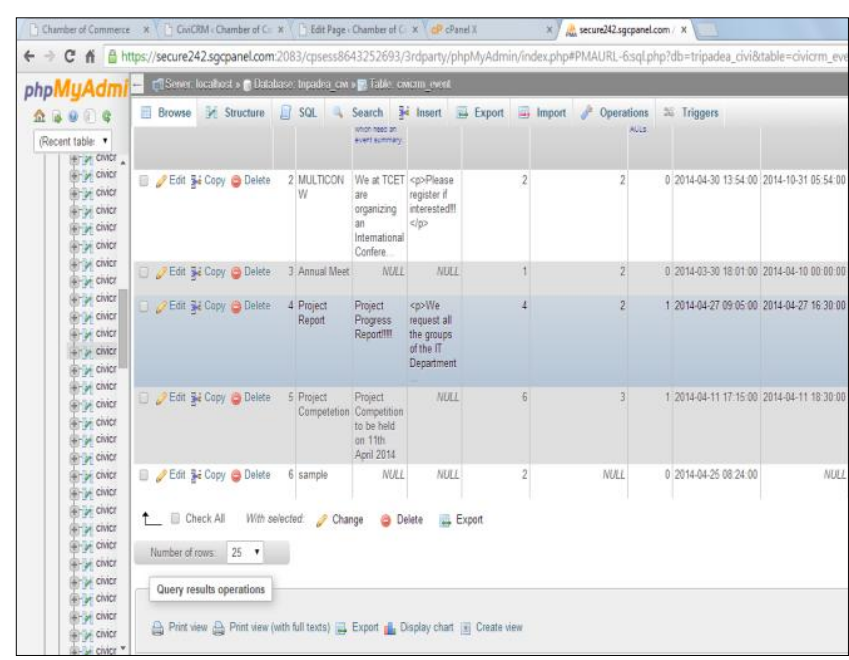

Fig 10: Event Registration Database view

\subsection{Issues}

WordPress doesn't support sessions. It is necessary that a member log should be maintained after the member signs into his account. This is necessary to track the members interests. This can be implemented by installing a plugin in WordPress. This will allow coding of the session in PHP on necessary member pages. Also, implementing CiviCRM needs training and assistance.

\section{RESULTS AND DISCUSSION}

Before implementation of CiviCRM for nonprofits, tailor made CRM software's were used to manage the services provided by the nonprofit. Also, excel sheets were used to manage events and mailing to members. There was no control to manage multiple data entries and maintain a clear view of the constituency.

The implementation uses CiviCRM with WordPress for building a software solution to handle members, events, donations, easy management and publishing of the content.

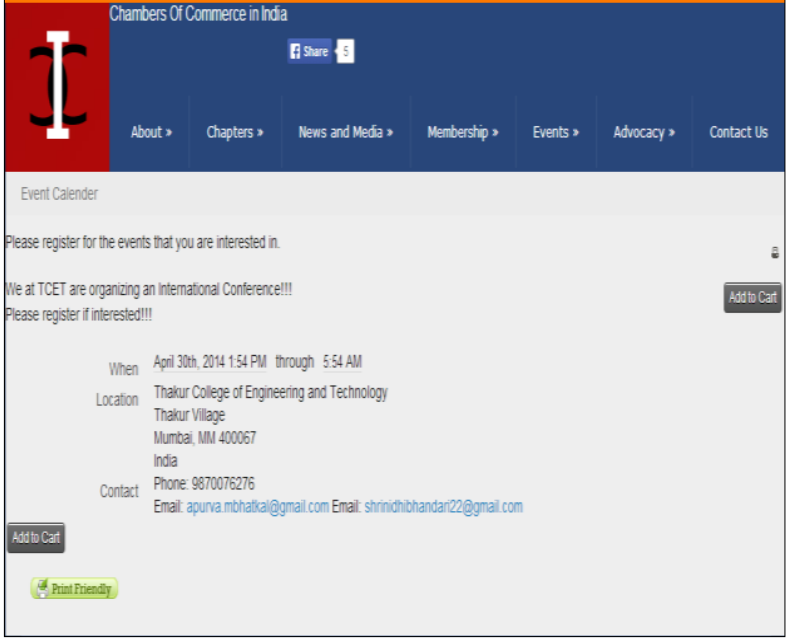

Fig 11: Event Registration User Interface

The most important reason for choosing CiviCRM is that; it is a customizable tool designed for nonprofits. It is cost effective and can handle the activities of the nonprofit.

Adding new contacts to the database, modifying them, connecting them by means of relationships and maintaining a consistent copy are some features that are important for the nonprofits. The automated system is used for managing memberships, events, sending emails before and after events. They are saved as templates and hence can be used later. This saves time. Sending emails and customizing newsletters are some key features to connect with the members. Managing the members and keeping a record of the payments and memberships can be efficiently handled. 


\section{CONCLUSION AND FUTURE SCOPE}

Impact of implementing CiviCRM on the nonprofits:

Implementing CiviCRM makes it easier to track member and event information than using Spreadsheets. An online membership directory is in sync with the member database. Hence there is no duplication of data. Also, the dynamic duo of the two allows the lay user to manage the content and information on the website.

Major concerns are with respect to security, setting up member sessions, translating the website to regional languages and handling the SEO of the website.

\section{ACKNOWLEDGMENTS}

We are foremost thankful to the Principal of our college Dr.

B.K. Mishra who has taken strenuous efforts in providing us with excellent lab facilities. We are also thankful to our Head of Department Dr.Vinayak Bharadi.

\section{REFERENCES}

[1] The Role of Non-Profit Organizations in Development: the Experience of the World Bank, Available [Online]: http://web.worldbank.org/WBSITE/EXTERNAL/TOPIC S/EXTSOCIALDEVELOPMENT/EXTPCENG/0,,conte DK:20507529 menuPK:1278313 pagePK:148956 piP K:216618 theSitePK:410306 isCURL:Y,00.html
[2] WordPress for Nonprofits Using CiviCRM, Available [Online]: http://www.slideshare.net/TadpoleCC/wordpress-for-nonprofits-using-civicrm

[3] WordPress, Joomla, and Drupal Magazine Web CMS Software, Available [Online]: http://www.advontemedia.com/blog/wordpress-joomladrupal-magaine-web-cms-software/

[4] CiviCRM Documentation, Available [Online]: http://wiki.civicrm.org/confluence/display/CRMDOC/Te chniques

[5] CiviCRM user and administrator guide, Available [Online]: http://book.civicrm.org/user/

[6] Managing non-profit organisations: Towards a new approach, Available [Online]: http://eprints.1se.ac.uk/29022/1/cswp1.pdf

[7] 10 Reasons To Use WordPress As Your CMS, Available [Online]: http://www.velvetblues.com/web-developmentblog/10-reasons-to-use-wordpress-as-your-cms/

[8] Elizabeth T. Boris; INTRODUCTION NONPROFIT ORGANIZATIONS IN A DEMOCRACY-ROLES AND RESPONSIBILITIES, Available [Online]: http://www.urban.org/books/npag2/upload/npag2_introd uction.pdf 